\title{
Green Roof Technology- Mitigate Urban Heat Island (UHI) Effect
}

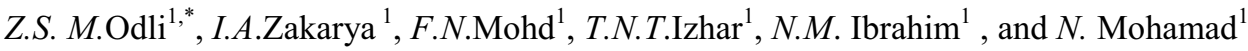 \\ ${ }^{1}$ School of Environmental Engineering, Universiti Malaysia Perlis (UniMAP), Kompleks Pusat \\ PengajianJejawi 3, 02600 Arau, Perlis, Malaysia
}

\begin{abstract}
Alterations on the land surfaces, which are attributed by human activities, especially in cities, cause many implications to the ecosystem. The increase of buildings in cities is reflecting the growth of human activities resulted in a significant temperature increase and warmer pattern in the urban area than the surrounding countryside. The phenomenon defined as urban heat island. This study investigates the application and efficiency of the green roof as an approach to mitigate urban heat island and reducing indoor temperature in a building. Two types of roof models, which consist of vegetative roof and non-vegetative roof, were built to investigate the efficiency of vegetated roof in reducing indoor temperature compared to the non-vegetated roof. The outdoor and indoor temperature and humidity of each roof model were monitored by using RH520 Thermo Hygrometer. The data was collected for three times in a week for 9 weeks at 9:00am to $5: 00 \mathrm{pm}$. It was found that the indoor average temperature data for vegetative roof could be reduced $2.4^{\circ} \mathrm{C}$ from the outdoor average temperature and $0.8^{\circ} \mathrm{C}$ for non-vegetative roof. The difference of temperature reduction for vegetative roof was greater than the nonvegetative roof, thus indicate that green roof was highly efficient in reducing indoor temperature and mitigate urban heat island impact.
\end{abstract}

\section{Introduction}

Global warming is described as when the temperature of the Earth's atmosphere is being increased. Continuous rise in global temperatures make the world warmer than it has been. Burning of fossil fuels, biomass burning, cement manufacture, cow and sheep rearing, deforestation and land-use changes are the activities that associated with the emission of greenhouse gases that posed to global warming scenario [1].

Presently, other environmental issues related to global warming and has created a concern is an urban heat island (UHI). The UHI is the phenomenon when the air temperature in the cities area is higher compared to suburban and rural areas (Figure 1) [2]. According to Davis [3], an area can be classified as undergo UHI when the ambient air temperature in downtown urban area is $2{ }^{\circ} \mathrm{C}-3{ }^{\circ} \mathrm{C}$ hotter than in rural areas. Urban heat is likely to raise a problem related to energy demand, human discomfort, air quality, and heat related diseases. With the increase of urban area and large cities, the problem is getting

\footnotetext{
* Corresponding author: zaity@unimap.edu.my
} 
more serious since the vegetative land surface is replaced with built surface. Generally, this will result in critical disruption on the role of the trees, which blocked the sun radiation during the day and hold in the heat at night and resulting to more extreme temperature swings at global level.

A study conducted by Rizwan et al. [4] shows that urban heat is mainly caused by the heat released from vehicles, power plant, air conditioner and heat from complex urban structures. Building materials such as concrete and asphalt have significantly different thermal and surface radiative properties than natural landscape, which absorb energy from the sun and convert it to sensible heat. Besides, it has been reported that UHI can be affected by certain ways like the lack of green spaces and water [5]. Another analysis made by Getter and Rowe [6], trace that the UHI phenomenon do not hit the urban only in the day, but also in the night since the absorbed heat is radiated back to the surrounding during the evening.

In response to the adverse impact of UHI towards the societies, many research works related to the studies on the concepts, methods, technologies and approach to mitigate the problem were iniated. Among the strategies that have been suggested, it is proven that increasing the green coverage with roof gardening and tree planting is one of the most effective way to mitigate the urban heat island phenomenon $[7,8]$. Therefore, application of green roof technology is the most attractive and relevant strategy to present the mitigation towards the UHI phenomena in the cities.

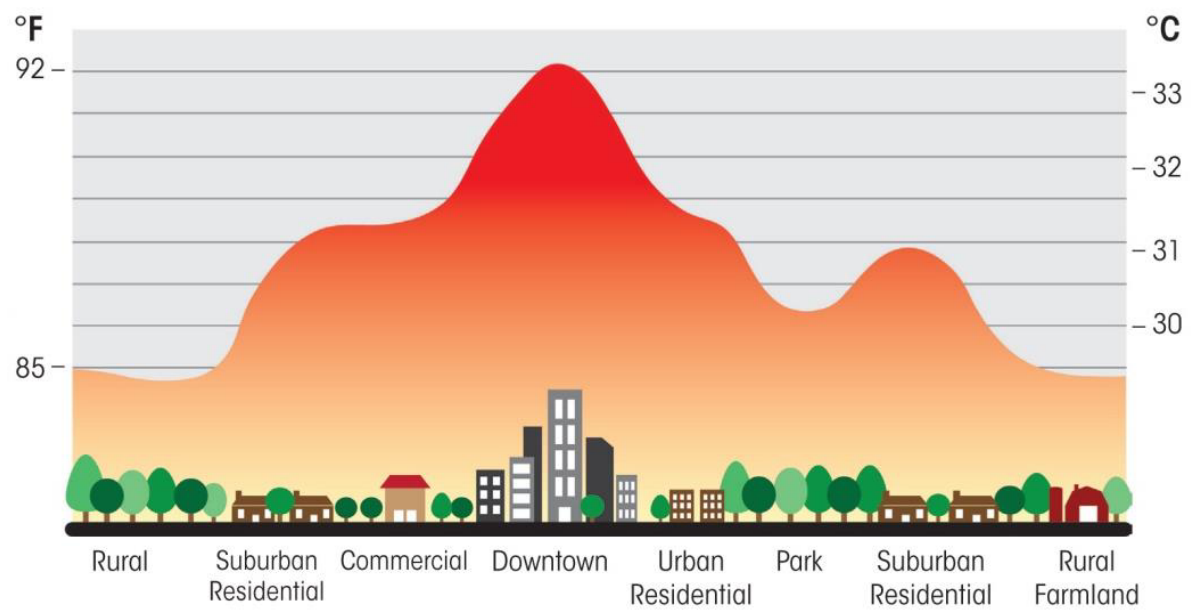

Fig. 1. Heat island profile [9].

Correspond with this issue, many related research for theses issues has been reviewed and discussed, and at the same time, the researchers have developed several recommendations on mitigation strategies to counteract the phenomenon. One of the strategies is green roof technology. Green roof technology is a technology of implementing vegetation and growing medium on the roof layer. Green roof offer high mitigation potential for high heat island problem [10].

Green roof or rooftop garden is a vegetative layer grown on a rooftop. A significance analysis from previous research stated that green roof promotes many economics, environmental, and social benefits [6]. Besides, Santamouris[10] has revealed that green roof presenting a great mitigation potential towards heat island phenomenon through vegetation usage. Firstly, plant and soils on the roof protects the surface below them by from direct sunlight radiation through shading. As a result, the temperature of the surface below the plants is reduced by the re-emitted of heat transmit into the atmosphere and the 
usage of sunlight by leaves for photosynthesis process [11]. Furthermore, the soils also acted to protect the underlying layers from UV radiation and strong wind [11]. However, amount of sunlight transmitted under the canopy of plants depends on plant species [12]. Secondly, green roof helps to reduce surface urban heat island through evapotranspiration. Evapotranspiration is the combination of evaporation and transpiration process is the process when liquid is converted into gas. Transpiration as explained by Monteith [13] is the condition when plants absorb water through their roots and emit it through their leaves (Figure 2).

\section{Evapotranspiration}

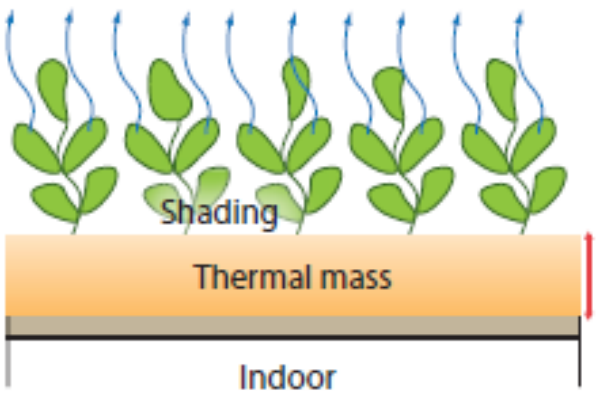

Fig. 2. Evapotranspiration and shading of a green roof [14].

\section{Methodology}

In this study, the observation and collection of the indoor temperature and humidity data were carried out on each roof model. The extensive roof models contain a layer of clay brick, roof, soil and vegetation. There are four extensive roof models, where three of them were planted with vegetation, which each consist a layer of Japanese grass (Zoysiatenuifolia), chives, joyweed (Alternantherasessilis) and one is non-vegetated roof. The extensive green roof has a soil thickness of 4 inch $(10.16 \mathrm{~cm})$ and total size of $144 \mathrm{inch}$ $\left(0.093 \mathrm{~m}^{2}\right)$. During the experimental period, a manual watering were provided with volume of $1.5 \mathrm{~L}$ to each green roof for twice a day which at every 9:00am and 5:00pm. The roof model with and without vegetative layer are presented in Figure 3.

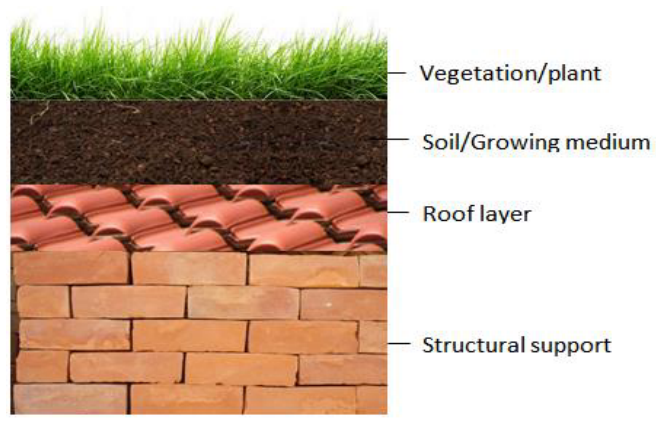

(a)

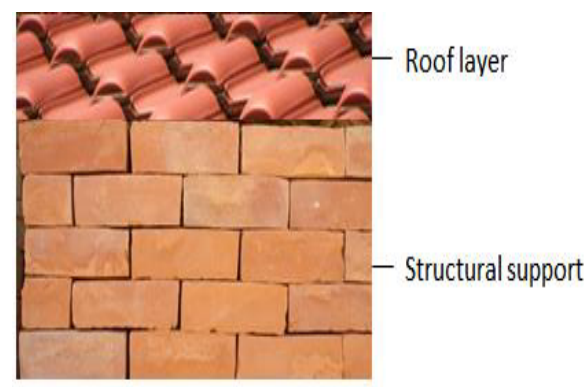

(b)

Fig. 3. The model of green roof with vegetation (a) and without vegetation (b). 
In order to investigate the effectiveness of the extensive roof model in reducing heat, the outdoor and indoor temperatures were monitored. The temperature and humidity below the roof surface in the structural support column of each roof model was defined as the indoor temperature and indoor humidity, while the ambient temperature and humidity outside of the structural support column and roof surface was defined as the outdoor ambient temperature and outdoor humidity. The temperature and humidity for both indoor and outdoor were recorded every 2 hours starting at 9:00am until 5:00pm for three days in a week for nine weeks using RH520 Thermo Hygrometer.

\section{Results and discussion}

The experiments were monitor continuously for 9 weeks between $27^{\text {th }}$ January until $25^{\text {th }}$ March 2016. The monitoring results and effectiveness of green roof were discussed as the following.

\subsection{Average temperatures for outdoor and indoor hardware roof models}

The average temperatures at different times for both outdoor and indoor of roof model are shown in Figure 4. The average temperatures data for the ninth week's show that indoor temperature of roof models has a lower reading than the outdoor temperature especially for the vegetation roof as compared to the non-vegetated roof. Moreover, to analyse the differences in term of effectiveness of the roof models at different times of the day, the average indoor temperature for each roof model was subtracted by the average outdoor temperature for every respective monitoring time. Table 1 compares the temperature difference of each period for blank, grass, joyweed and chives roof model from the average ninth weeks monitoring period values.

\begin{tabular}{|c|c|c|c|c|c|c|}
\hline \multirow[t]{7}{*}{ 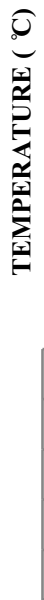 } & $\begin{array}{r}40.0 \\
35.0 \\
30.0 \\
25.0 \\
20.0 \\
15.0 \\
10.0 \\
5.0\end{array}$ & 1 & & & & \\
\hline & & 9:00am & $\begin{array}{c}11: 00 \mathrm{a} \\
\mathrm{m}\end{array}$ & $1: 00 \mathrm{pm}$ & 3:00pm & $5: 00 \mathrm{pm}$ \\
\hline & Avg. Outdoor Ambient air & 27.6 & 32.5 & 35.5 & 35.5 & 34.2 \\
\hline & Avg. Indoor Blank Roof & 26.8 & 32.3 & 35.5 & 35.3 & 34.0 \\
\hline & Avg. Indoor Grass Roof & 26.5 & 30.1 & 33.2 & 33.8 & 33.2 \\
\hline & Avg. Indoor Joyweed Roof & 26.6 & 30.2 & 33.4 & 33.9 & 33.3 \\
\hline & Avg. Indoor Chives Roof & 26.6 & 30.6 & 33.5 & 33.9 & 33.2 \\
\hline
\end{tabular}

Fig. 4. Average temperature at different times for outdoor and indoor roof models.

Table 1 illustrates the temperature difference for each roof model. The highest difference of outdoor and indoor temperature for each period is from grass roof model, followed by joyweed, chives and blank roof models. The greatest difference of outdoor and indoor temperature was recorded at $2.4^{\circ} \mathrm{C}$ from grass and joyweed roof model during 11:00am with efficiency of $7.4 \%$, while the lowest difference is from blank roof model during 1:00pm. 
Table 1. Difference of outdoor and indoor temperature.

\begin{tabular}{|l|c|c|c|c|c|c|c|c|c|}
\hline Time & $\begin{array}{c}\text { Average } \\
\text { outdoor } \\
\text { temperature } \\
\left({ }^{(} \mathbf{C}\right)\end{array}$ & \multicolumn{3}{|c|}{ Average indoor temperature $\left({ }^{\circ} \mathbf{C}\right)$} & \multicolumn{3}{|c|}{$\begin{array}{c}\text { Difference of outdoor and indoor } \\
\text { temperature }\left({ }^{\circ} \mathbf{C}\right)\end{array}$} \\
\cline { 5 - 11 } & Blank & Grass & Joyweed & Chives & Blank & Grass & Joyweed & Chives \\
\hline $\mathbf{9 : 0 0 a m}$ & 27.6 & 26.8 & 26.5 & 26.6 & 26.6 & 0.8 & 1.1 & 1.1 & 1.0 \\
\hline $\mathbf{1 1 : 0 0 a m}$ & 32.5 & 32.3 & 30.1 & 30.2 & 30.6 & 0.3 & 2.4 & 2.4 & 1.9 \\
\hline $\mathbf{1 : 0 0 p m}$ & 35.5 & 35.5 & 33.2 & 33.4 & 33.5 & 0.0 & 2.3 & 2.1 & 2.0 \\
\hline $\mathbf{3 : 0 0 p m}$ & 35.5 & 35.3 & 33.8 & 33.9 & 33.9 & 0.2 & 1.7 & 1.6 & 1.6 \\
\hline $\mathbf{5 : 0 0 p m}$ & 34.2 & 34.0 & 33.2 & 33.3 & 33.2 & 0.3 & 1.0 & 0.9 & 1.0 \\
\hline
\end{tabular}

Based on these figure and table, the significant cooling period for the vegetative roof model was at 11:00am to $1: 00 \mathrm{pm}$. During this time, the vegetation and soil layer act efficiently in insulating the roof from direct radiation hit from the sun.

\subsection{Average humidity for outdoor and indoor hardware roof models}

Aside from temperature, humidity also influences the cooling process in the indoor roof model. Comparing the average humidity data for both outdoor and indoor humidity, simple data tabulation was made. Figure 5 shows the experimental data on average outdoor humidity and average indoor humidity of roof model. From the figure, the highest average humidity for both outdoor and indoor were recorded at 9:00am with humidity range from $73-78 \%$ while the lowest humidity range was recorded at 3:00pm with range of $41-51 \%$. From the entire roof model, the indoor of the grass roof model reported more humid than the other three roof models and the outdoor humidity.

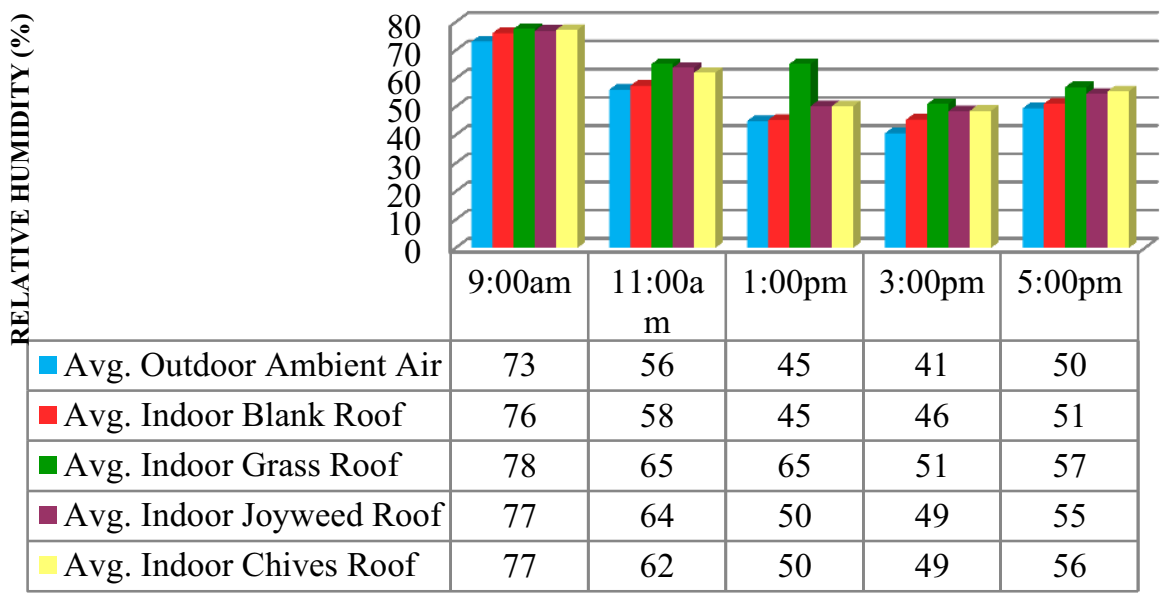

Fig. 5. Average humidity at different times for outdoor and indoor roof models.

As can be seen from Table 2, the highest humidity difference was displayed by grass roof model at 9:00am with difference of $20 \%$ from the outdoor humidity, while for joyweed, the highest difference in humidity was achieved at 11:00am with 8\% humidity 
difference and as for chives, the highest humidity difference wasis $8 \%$ at 3:00pm. As for blank bare roof, the indoor humidity recorded the highest difference reading at 3:00pm with $5 \%$ humidity difference with the outdoor humidity. The outdoor humidity was basically greatly influenced by the cloud which shade the sun, and wind speed of the environment.

Table 2. Difference of outdoor and indoor humidity.

\begin{tabular}{|l|c|c|c|c|c|c|c|c|c|}
\hline Time & $\begin{array}{c}\text { Average } \\
\text { outdoor } \\
\text { humidity } \\
\text { (\%) }\end{array}$ & \multicolumn{3}{|c|}{ Average indoor humidity (\%) } & \multicolumn{3}{c|}{$\begin{array}{c}\text { Difference of outdoor and indoor } \\
\text { humidity (\%) }\end{array}$} \\
\cline { 3 - 10 } & Blank & Grass & Joyweed & Chives & Blank & Grass & Joyweed & Chives \\
\hline 9:00am & 73 & 76 & 78 & 77 & 77 & -3 & -5 & -4 & -4 \\
\hline $\mathbf{1 1 : 0 0 a m}$ & 56 & 58 & 65 & 64 & 62 & -1 & -9 & -8 & -6 \\
\hline $\mathbf{1 : 0 0 p m}$ & 45 & 45 & 65 & 50 & 50 & 0 & -20 & -5 & -5 \\
\hline $\mathbf{3 : 0 0 p m}$ & 41 & 46 & 51 & 49 & 49 & -5 & -10 & -8 & -8 \\
\hline $\mathbf{5 : 0 0 p m}$ & 50 & 51 & 57 & 55 & 56 & -2 & -7 & -5 & -6 \\
\hline
\end{tabular}

Overall, these results indicate that the vegetative roof was better at reducing indoor temperature and offer significant cooling state for the indoor condition than non-vegetative roof. These finding were supported by the result from the study by Rosenweig et al. [15], where green roof provides a cooling effect to the city by $2-3 \mathrm{~K}$ compared to cooling effect by the non-green roofs. Moreover, from this result, it was explained that grass was the best choice of plant to be used as green roof instead of joyweed and chives since grass provided high temperature and humidity difference. However, from the observation, the three types of plant used as green roof was highly sun tolerance, which can survive 3 days without water in hot day based on the Perlis climate.

\section{Conclusion}

Comparing the effectiveness of the green roof and non-green roof, a significant difference in indoor temperature and humidity with the outdoor temperature and humidity was found. It was confirmed that the indoor temperature of the hardware roof model for extensive green roof was lower than the indoor temperature of the hardware roof for extensive nongreen roof. Extensive green roof also has higher humidity as compared to extensive nongreen roof. The cooling effectiveness of the extensive hardware green roof model was significant when the ambient air temperature started to increase especially from 11:00am to $3: 00 \mathrm{pm}$. Besides, it is confirmed that vegetation and soil help in react as an insulator for the roof form receiving high direct radiation form the sun. To conclude, applying vegetation of roof can reduce the impact of urban heat island.

\section{References}

1. S. Solomon, D. Qin, M. Manning, Z. Chen, M. Marquis, K.B. Averyt, M. Tignor, H.L. Miller, Climate change 2007: The physical science basis (Cambride University Press, Cambride, United Kingdom, 2007)

2. M. Santamouris, Solar Enery: The State o Art (James and James Science Publishers, London, 2001)

3. M.P. Davis, N.A. Nordin, M. Ghazali, M.J. Durak, G. Reimann, Conference on Sustainable Building South East Asia, Malaysia (2005) 
4. A.M. Rizwan, L.Y. Dennis, L.I.U. Chunho, Journal of Environmental Sciences, 20, 120 (2008)

5. N.H. Wong, H. Feriadi, P.Y. Lim, K.W. Tham, C. Sekhar, K.W. Cheong, Building and Environment, 37, 1267 (2002)

6. K.L. Getter, D.B. Rowe, HortScience, 41, 1276 (2006)

7. M.A. Hart, D.J. Sailor, Theor. Appl. Climatol., 95, 397 (2009)

8. Z. Ismail, M. Makmor, R. Hashim, R.M. Shah, N.A. Hanifah, S. Ahmad, IEEE Colloqium on Humanities, Science \& Engineering Research (2012)

9. Ahmed Rizwan, Journal of Environmental Science, 20,120 (2008)

10. M. Santamouris, Sol. Energy, 103, 682 (2014)

11. Green Roofs, Reducing Urban Heat Island: Compendium of Strategies (U..S. Environmental Protection Agency's Office of Atmospheric Programs, U.S., 2015)

12. R. Arabi, M.F. Shahidan, M.M. Kamal, M.F.Z.B. Jaafar, M. Rakhshandehroo, Current World Environment, 10, 918 (2015)

13. J. Monteith, Symp. Soc. Exp. Biol., 19, 205 (1965)

14. K. Liu, B. Bass, Performance of Green Roof Systems (National Research Council Canada, Toronto, Canada, 2005)

15. Rosenzweig Cynthia, William Solecki, Ronald Slosberg, A report to the New York State Energy Research and Development Authority (2006). 